\title{
The energy ecology in agriculture: the concept, application and management
}

\section{Book review}

Energy is the prime mover of economic growth, and is vital to sustaining a modern economy and society. In Agriculture energy is the most important input that promotes sustains and directs both production and productivity but Indian farmers are more input illiterate and less energy educated. The indiscriminate consumption of energy, as has been reflected in water management, soil and nutrient management, even in part of processing agriculture, will lead to a catastrophic ecology in Indian farming. ${ }^{1}$ The relation between agriculture and energy is very close. Agriculture itself is an energy user and energy in the form of bio-energy. Energy use in agriculture has developed in response to increasing an increasing standard of living. In all societies, these factors have encouraged an increase in energy inputs to maximize yields, minimize labor-intensive practices, or both. Effective energy use in agriculture is one of the conditions for sustainable agricultural production, since it provides financial savings, fossil resources preservation and air pollution Reduction. Application of integrated to reduce production costs, to efficiently use human labor and other inputs and to protect the environment. Agricultural productivity is closely linked with the energy. There is directly energy input (derived from mean, animal, electric motors, engines, power tiller and tractors) required for seedbed preparation, sowing or panting, inter-culture weed control, irrigation, harvesting and threshing, transportation, and there are indirect energy input (in the form of seed, fertilizers, organic manures, pesticides, growth regulators, machinery, and structures) which need varying amount of commercial and non-commercial energy source. The case and effect of global warming are basically rooted into the thermal emission, its retention and scattering into the atmosphere, which again can well be attributed substantially to the energy consumption pattern, both in urban and rural families as well as institutions. Any ecosystem in this universe needs energy as the driving force to maintain the system functioning and system behavior and it's no exception to farming ecosystem. The efficient energy consumption, generation and transfer have become a subject not only related to technology and input but also related to management and planning which again is socio-ecological in nature. Efficient energy management practices will help achieve and maintain this delicate balance. A reliable supply of energy, in the right from, at the right time and at affordable prices, is an essential prerequisite for high agricultural productivity. Energy is the ability or capacity to do work, and work is moving something against a force, like gravity. Energy exists in two forms potential and kinetic. Potential energy is the energy at rest \{i.e., stored energy) capable of performing work. Kinetic energy is the energy of motion (free energy). Energy is the basic driver for any kind of ecological entity, big or small, medium, or humongous. Energy in Agricultural Ecological has certainly characterized its two basic functions-The production function and the system function.

\section{Energy use in agro ecosystem}

In India, energy use in agriculture has been increasing since

\author{
Volume 6 Issue 5 - 2017 \\ Lokesh Kumar Tinde, 'Acharya SK,' Arbind
Kumar Sai ${ }^{2}$ \\ 'Department of Agricultural Extension, Bidhan Chandra Krishi \\ Viswavidyalaya India \\ ${ }^{2}$ Department of Agricultural Extension, Narendra Dev \\ University of Agriculture and Technology, India
}

Correspondence: Lokesh Kumar Tinde, Department of Agricultural Extension, Bidhan Chandra Krishi Viswavidyalaya Mohanpur District-Nadia West Bengal, 74I252, India, Email tinde.lokesh744@gmail.com

Received: February 23, 2017| Published: March 07, 2017

Green Revolution in the late sixties increasing use of high-yielding seed varieties, synthetic fertilizers, agro-chemicals, as well as diesel and electricity in farm operations. The pattern and rate of growth of demand for energy source is influenced by a number of factors such as increasing population, growing urbanization, rising household income, changing life-style and structural changes taking place in the economy. Increase in land productivity and efficient diversification of agriculture for better economic return to the producer call for significantly higher level of energy input to agriculture. Agricultural experts all over the world have marshaled ample evidence to support that energy use per hectare has direct bearing on the crop yield. The Indian agriculture has witnessed a tremendous transformation since Independence, particularly owing to the 'Green Revolution' of the sixties. As a result, the food production has increased about more than four-fold, leading the country toward self-reliance and food security. ${ }^{2}$ Agriculture in India has gone into more or less total transformation from organic to inorganic agriculture. Increasing use of commercial energy has made agriculture move with fast stride. Energy as an input is attaining higher demand with the growth of agriculture production. A significant aspect of agriculture and energy is the interactive relationship between energy and other agricultural production input. Agricultural productivity is closely linked with the energy. There is directly energy input (derived from mean, animal, electric motors, engines, power tiller and tractors) required for seedbed preparation, sowing or panting, inter-culture weed control, irrigation, harvesting and threshing, transportation, and there are indirect energy input (in the form of seed, fertilizers, organic manures, pesticides, weedicides, growth regulators, machinery, and structures) which need varying amount of commercial and non-commercial energy source. ${ }^{3}$ Factors that have contributed to increase in agriculture production are technology advancement, improved irrigation practices and increased area under irrigation, improved seeds, use of fertilizers, use of pesticides, improved agricultural implements and machinery, agricultural credits and rural banking and improved marketing and support price. 


\section{Energy and socio-economic development}

Energy is central to achieve the interrelated economic, social, and environmental aims of sustainable human development. The relationship between use of energy and economic growth has been a subject of greater inquiry as energy is considered to be one of the important driving forces of economic growth in all economies Energy has been universally recognized as one of the most important catalysts for economic growth and human development. Energy is the prime mover of economic growth, and is vital to sustaining a modern economy and society. Future economic growth significantly depends on the long term availability of energy from sources that are affordable, accessible and secure. 'Energy's the basic need of human beings. It is an integral component of a modern economy and is an essential ingredient in nearly all goods and services. All the activities taking place in the nature are the transformation of energy from one form or the other. The relation between agriculture and energy is very close. Energy use in agriculture has developed in response to increasing an increasing standard of living. In all societies, these factors have encouraged an increase in energy inputs to maximize yields, minimize labor-intensive practices, or both. Effective energy use in agriculture is one of the conditions for sustainable agricultural production, since it provides financial savings, fossil resources preservation and air pollution Reduction. Application of integrated to reduce production costs, to efficiently use human labor and other inputs and to protect the environment. Agriculture must be compatible with both society's needs and the natural ecosystem. Rapid population growth and the technical development of society have led to difficulties for farmers worldwide to maintain this dual compatibility. In fact, today farmers face demands for a high productivity as well as environmentally sound, sustainable farming practices. In rural, developing societies, local environmental constraints historically shaped techniques of production and socioeconomic structures. Agricultural strategies and social activities favored long-term ecosystem sustainability. However, the quality of life reached by traditional farming systems is low compared with that of modern western agricultural systemsshort life span, low level of education, and absence of social services, etc. In other words, "subsistence farming systems" are economically not sustainable when these societies interact with more developed socioeconomic systems. All societies require energy services to meet basic human needs (e.g., lighting, cooking, space comfort, mobility, communication) and to serve productive processes. For development to be sustainable, delivery of energy services need to be secure and have low environmental impacts.

\section{Energy management and sustainability issues}

Energy is a scarce resource, at least for some groups of people in some places and, maybe, for the world as a whole. A rational use of energy is then necessary for economic and environmental reasons. This applies to agriculture as much as to any other sector of the economy. A key to the rational use of energy is the understanding of the role of energy. It should help communication between agricultural planners and energy specialists. With increasing demand on commercial energy resource in production and processing of agro-produces. Energy management would play a key role in developing regional/national coherent and implementable strategies for energy conservation, adopting energy efficient technologies as well as determining an appropriate energy resource-mix of conventional and renewable energy resources for minimizing energy $\operatorname{cost}^{4}{ }^{4}$ A reliable supply of energy, in the right from, at the right time and at affordable prices, is an essential prerequisite for high agricultural productivity. Smart energy management systems allow businesses to dramatically reduce their overall running costs. Smart Energy Management is about much more than simply teaching people to turn off the lights when they leave a room. This is about energy reduction strategies and solutions and the integration of a fully automated smart system that can provide your business with total control over your energy consumption and reduce the costs of doing business. As the population continues to grow, more agricultural production is required to support the increased demand. At the same time, energy and environment constraints mandate that agricultural production be accomplished effectively with minimal energy consumption. It is necessary to increase agricultural yield per unit area of land, while preserving the soil integrity and environment.

\section{Conclusion}

Efficient energy management practices will help achieve and maintain this delicate balance. Renewable Energy offers opportunity to contribute to social and economic development, energy access, secure energy supply, climate change mitigation, and the reduction of negative environmental and health impacts. As the population continues to grow, more agricultural production is required to support the increased demand. At the same time, energy and environment constraints mandate that agricultural production be accomplished effectively with minimal energy consumption. It is necessary to increase agricultural yield per unit area of land, while preserving the soil integrity and environment. Farming systems for sustainable crop production intensification will be built the simultaneous achievement of increased agricultural productivity and enhancement of natural capital and ecosystem services, use of managed and natural biodiversity to build the system resilience to a biotic, biotic and economic stresses. Using management practices: minimum soil disturbance, permanent organic soil cover, use of high-yielding adapted varieties from good seed, integrated pest management, plant nutrition based on healthy soils and efficient water management. Farm Energy auditing, through a modified extension policy, shall be incorporated in the farm management activities by the department of agriculture and allied sectors.

\section{Acknowledgements}

The authors hereby acknowledge the improvement brought about in this paper due to the valuable comments of editors and referee.

\section{Conflict of interest}

The author declares no conflict of interest.

\section{References}

1. Pal T. Farm Energy Management: The perceived impact on social ecology at the community level. Department Agricultural Extension Bidhan Chandra Krishi Viswavidyalaya West Bengal; 2016.

2. Pandey MM, Sirohi NPS, Ganesan S, et al. Handbook of agriculture engineering. Directorate of Information and Publication of Agriculture. (DIPA) ICAR New Delhi India; 2013. p. 373-409.

3. Pradhan P, Naik RK, Manisha S, et al. A study on the energy use pattern and cost of production under transplanted paddy production system in Chhattisgarh, India. International Journal of Engineering Research \& Technology. 2015;4(7):2278-0181.

4. Ediger VS, Huvaz O. Examining the Sectoral Energy Use in Turkish Economy (1980-2000) with the Help of Decomposition Analys. Energy Conversion and Management. 2006;47(6):732-745. 